\title{
Economization of Information and Scientific Data: A Common Approach
}

Submitted $12 / 12 / 18,1^{\text {st }}$ revision $6 / 1 / 19,2^{\text {nd }}$ revision $15 / 2 / 19,3^{\text {rd }}$ revision $22 / 2 / 19$ accepted $1 / 3 / 19$

\author{
Belikova K.M. ${ }^{1}$, Badaeva N.V. ${ }^{2}$, Akhmadova M.A. $^{3}$ \\ Abstract:
}

The authors present a study on the economization of information and scientific data in the current information society that creates grounds for the rapid development of the economy of knowledge.

The study reveals that both information and scientific data became the object of attention of economists who tried to explain the behavior of scientists and groups of scientists (research communities) from a standpoint of not only 'disinterestedness' in scientific research, but also in the context of striving to optimize their costs and earns.

Keywords: Science, information, scientific data, economization, economic theory, scientists, myth, costs, optimization.

JEL codes: A12, B30, C70, D18, D21, D84, O30, O33.

\section{Acknowledgment:}

The reported study was funded by RFBR according to the research project № 18-29-15030 mk on the theme "Scientific information in the orbit of the content, forms and problems of intellectual property rights protection (comparison with regard to the experience of BRICS countries)" (Grantee - Dr. of Sciences, Prof. Ksenia M. Belikova, Peoples' Friendship University of Russia (RUDN University), www.rudn.ru)

\footnotetext{
${ }^{1}$ Doctor of Science (Law), Professor, Professor of the Department of "Civil Law and Proceedings and International Private law”, Peoples' Friendship University of Russia (RUDN University),Moscow, BelikovaKsenia@yandex.ru

${ }^{2}$ Candidate of Science (Law), Associate Professor of the Department of "Civil Law and Proceedings and International Private law”, Peoples' Friendship University of Russia (RUDN University), Moscow, natalya_b7@mail.ru ${ }^{3}$ Post-graduate of Department of Civil Law and Proceedings and International Private Law, Peoples' Friendship University of Russia (RUDN University), 4ernijkvadrat95@gmail.com
} 


\section{Introduction}

Just as modern legal science reveals an ever-increasing need for using the methods of economic science to study many legal phenomena, the unclear at first glance connection of information with the economic science is increasing. Especially now, when the current society could be already an information society, a society operating at a qualitatively new level, at which a significant part of the working population carries out either production, storage, processing, or sale of information, including its highest form - the knowledge. This will be seen below on the example of various economic studies. Here we note that the most general definition of economics, treated from the standpoint of competition, pursued goals and limited funds, is caused by specific problems that need to be solved and therefore, not limited to the market sector, involves a much larger sphere of life activities.

Any resources can be characterized by the rarity of their location and the need to make choices that need to be made with any form of resource allocation, ranging from the level of public policy (making decisions about the amount of taxation, the need to change legislation or implement construction of public facilities, etc.) to the level of the family (family planning, determination of the place of residence, work, education of children, etc.). There is also a constant choice in the scientific field regarding the determination of scientific research area, their organization both from the standpoint of the number of researchers and their validation, and from the standpoint of their personal time allocation (for rest, work to solve this and other tasks). There are numerous examples of the need to make daily choices in people's lives (Becker, 1987).

Talking about the scientific beginnings of knowledge, later transforming into scientific information and data, it should be noted that initially they emerge from myths by transforming the original meanings of mythological traditions. They occur in the process of movement and the development of knowledge until the changes formed during the interpretation of myths and the result could not be attributed to myths as such. At the same time, the question may immediately arise: what is the purpose of this orientation and why does every change occur precisely this way?

There is an opinion that a man, being a purely biological being and therefore weak, was doomed to complete extinction, and for his survival he had to find any tools that could effectively ensure his continued existence and activity. And one of the powerful tools of survival was science as a special result of human activity in the sense of knowing the world around us. The science became the result of using the known for their own selfish purposes, and then - domination, rule, economic management, the subordination of the nature forces, the transformation of the world, etc., (Baturin, 2010).

At the same time, knowledge and experience acquired by a person and necessary for its further existence are always dichotomous and presented both as an essential side 
(answering the question "what is it?") and axiological, value, evaluating side (answering the question "what is it for?"). That is, scientific knowledge is always the unity of essence and value, essential and axiological. Human activity itself is fundamentally dichotomous and has both a cognitive and amazement component of activity, aimed at managing what has been revealed and found at the stage of cognition of the surrounding world. Let us follow how the issue of the economization of scientific data was solved in the past and is solved at the present stage.

\section{Methodology}

In this article, the authors proceeded from the objectively - subjective assignment of any phenomena and processes of the external world. In this format, general scientific (formal and dialectical logic combined with analysis and synthesis, induction and deduction, hypothesis and analogy) and special (comparative, historical, system analysis) research methods were utilized in the study.

\section{Results}

A retrospective analysis and analysis of the current state of the economization of information and scientific information, as well as the essence of scientific knowledge vs. myth, allows us to consider science, firstly, as a system of scientific knowledge, secondly, as an activity of subjects aimed at understanding the patterns of various phenomena, thirdly, as a social institute uniting scientists, scientific schools, research organizations and solving various tasks, ensuring private interests, coupled with interest of groups. At the same time, the inextricable link between data, science, scientific knowledge, scientific information and information was revealed with increasing role of knowledge in the structure of the national wealth of modern states. It was shown that knowledge is a form of information and therefore subjective, while information is of objective nature.

Being a special subject of regulation from the standpoint of sociology, law, economics, scientists are institutionally supported in their activities both by the desire of each for professional recognition, and by the benefits expected from scientific activity. Of course, this affects the nature and content of scientific information selected by scientists for the development, promotion, propaganda as scientific knowledge.

\section{Discussion}

The basis of scientific data is the concept of 'information'. The first appeal to information is found in the works of the classics of economics A. Smith and D. Riccardo, who regard a person as an economic subject whose behavior corresponded to a model, in which, along with his own interests and mental abilities, his knowledge was also taken into account (Bokanov, 2010). 
Economic theory, like law, speaks about the importance of information for market relations and determines the market of perfect competition based on the concept that each market participant (sellers and buyers) have complete reliable information on prices, quantity of products, costs and demand in the market (Lvov, 1992; Belikova, 2012).

Knight (2000), based on purely economic preconditions in defining the concepts of 'uncertainty' and 'risk', formulated a concept on the basis of which uncertainty is caused by the presence of a time gap between the moments of decision making and their implementation, during which unexpected changes in the market can occur as fluctuations in commodity prices, leading to the risk of participants' transactions. From the standpoint of this concept, information acts as a concept opposite to uncertainty and inversely proportional to risk. That is, the risk is the probability of the implementation of any event, the uncertainty is not possible to estimate, and the information is what allows one to believe in reliable and certain possibility of the event. Thus, the risk occurs when the information is incomplete, but the more complete the information, the less is the risk.

Later Coase (1937) and Hart (1942), who investigated the strategic behavior of a company in the capital market without touching the essence of the information in their research, revealed that the production cycle is impossible without constant replenishment with new information. So, for example, Coase pointed out that when managing under market conditions, there are costs of a special kind, called 'transactional' (Latin transactio is a deal). For example, they include the costs of collecting information about price, consumer preferences and competitor intentions, as well as organizational costs associated with negotiations, concluding transactions and their legal support. If, according to economic theory, a producer of goods has the right to change a transaction partner at any time, then actually relations of economic entities are based on contracts of different duration, and their cancellation requires reasonable justification, and renewal requires extra costs. In this regard, when the value of the transaction starts to be considered, it is easier to explain the existence of various firms and corporations, their associations, as well as the existing agreements in various ways, etc.

Attempts were also made to define information as an economic category. Stonier (1986) argued about the indivisibility of information, reducing this thesis to the formula "if I have a certain amount of information and I shared the half of it with another person, I have everything that was". Maiminas (1997) identifies the following features of the information as an economic category: the inability to unambiguously assess the value of information received, since the latter is a commodity that is worth its price to pay; information is characterized by a different mechanism of aging than the one of fixed assets and consumer goods. The consequence of this is its dualism: on the one hand, the availability of information about the possibility of an event to a certain point raises its price before the onset of this event, and then loses in price completely at a certain point in time, on the other, 
historical data on any event (object) increases in price so far as the information they are based becomes obsolete. The application of economic studies also took place in the scientific field. For example, in the works of Merton (1973), Stigler (1976), Becker (1987), the economic approach does not simply reformulate various forms of behavior in a language familiar to economists, but also gives a justification.

Because evaluation of scientific information comes up against the fact that it is obviously not a product of mass production, comments were often made that Karl Marx's labor theory of value was not able to explain the realities of information production with proper reflection on scientific information in the cost category. On the other hand, there is also an opinion that, at the level of universal cognition, information is not capable of being perceived as a product of human labor because man is not an inventor, but only a discoverer of the laws of nature. "As a miner with his pickaxe cuts out new ores from the rocks, the scientist calls out of darkness a new being, which he does not create, but reveals and frees him to life" (Bulgakov, 1990).

From this point of view, the result of basic research cannot be a part of a sale and purchase transaction as an object, and information, which is a product of basic sciences, becomes an unlimited and free resource, the use of which is not determined by the direct value expression. And the products that are the result of research in applied fields, are used precisely outside the scope of research. For this reason, along with abstract-theoretical, they have practical value, and commodity and other relations arise during their social movement. In this format, on the one hand, according to the economic approach, a person decides to perform an action when his expected utility exceeds the expected usefulness of life without this action, or additional costs arise if life continues until the action is performed.

On the other hand, both economists and sociologists consider both science and scientists from the position of their ethical research. Merton (1973) for example, proposed to consider the scope of the concept 'ethos' (professional behavior of a scientist) of science to be revealed from the perspective of four concepts: 'universalism', 'collectivism', 'disinterested' and 'organized skepticism'.

These maxims were followed by several rules emerged for scientists. In particular, a scientist should: 1) try to obtain such knowledge that would be highly appreciated by colleagues, but at the same time he should not pay attention to the assessment of others, while working; 2) always keep in mind the fact of the universality of knowledge, but do not forget that any scientific discovery enhances the recognition of the nation whose representative made it; 3) to participate in the education of a new generation of scientists, without giving too much time and attention to this training; 4) study under the great masters, imitate them, but not to be like them, etc. (Mirskaya, 2005). However, from the standpoint of economic theory, not all these maxims are effective. 
Thus, in accordance with the Heisenberg uncertainty principle, Stigler (1976) believed that the studied phenomena of modern physics cannot usually be observed in the "natural" state because observation could change these phenomena. Regarding social scientists, he formulated an even more radical view that they act not only as researchers, but also as participants in the social process and, therefore, are not objective in their observations (here the principle of 'skepticism' by Merton is violated).

Thus, the economic approach is on a different, but remotely, something like other positions: people decide whether to engage in scientific, intellectual or creative activity only when they expect this benefit (monetary, psychological), which are superior to those that they could get in other occupations. Considering that the same criterion is used when choosing more ordinary professions, there is no reason for supporters of intellectual professions to show less concern about their remuneration, to think more about the public good and to be more honest than everyone else 'by nature' (here the principle of 'Disinterestedness' by Merton is violated).

Indeed, ideas about the scientific problem, the subject of research, methods of conducting research, the expected scientific result were developed, for example, in Russia, and earlier in the pre-revolutionary (Shershenevich, 2003) and the Soviet period (Ioffe, 2000). However, now they no longer fully reflect modern ideas on conducting the scientific activity in general, and do not meet the expectations associated with science. Often a market economy gives grounds for studies from the standpoint of the principle of 'disinterestedness' (not necessary, but profitable studies). And here it becomes obvious that the obtained scientific result depends on the correct choice of a scientific problem, the definition of the subject research field and the methods used. This is especially important in the context of accepting or not accepting the ideas of Kuhn (1977) about a successive change of paradigms, or about the presence of paradigms in the field of one or another subject title, developing in parallel, simultaneously. At the same time, it is extremely important to keep in mind that scientific paradigms building their own system of knowledge, explaining the essence of a particular subject area, are formed depending on the researcher's personal response to a number of questions in this area, which, in our opinion, could be directly considered from the perspective of non-market behavior of individuals within the framework of economic theory. And some make such attempts (Filippova, 2018).

The authors of this study believe that every scientist, when conducting research and obtaining a scientific result, is bound by his own implicit knowledge i.e., the system of postulates and attitudes of the scientific school he refers to (here the Merton's principle of scientific 'collectivism' is supported). Of course, we should agree with this. The since, although the actual research activities of a scientist, like any process, phenomenon, etc., have a subjective-objective feature. One should not underestimate the personality of a research scientist, his personal contribution to the scientific result, that is, the subjective component of the research process (however, the 
principle of Merton's 'universalism' is also violated, because the subjective in one way or another overcome the universals, there is no ultimately extra-personal scientific knowledge, just mind the famous "Plato is my friend, but the truth is more precious").

We note that now in Russia, for example, conferences and other scientific events are held (Belikova, 2013), where problems of methods of conducting research activities are discussed, for example, in civil law, etc. The relevant educational courses (RUDN, 2018) are taught in higher educational institutions, but the formation of a systemic view of science and its methodology at the present stage is still very far away. The criteria for scientific knowledge by Merton were later supplemented by Barber (1952) with ones like 'rationalism' and 'emotional neutrality'. The latter seems to us like the 'selflessness' and 'organized skepticism' mentioned above. In the format of such representations, basing on the fact that one of the functions of information is its utilization in the processes of material and spiritual production facilitating the success of human labor, the information reduces the social cost of products and develops new products of labor to meet the social needs. Schematically, the interaction of science, scientific knowledge, scientific data and information can be presented as follows in Figure 1.

Figure 1. Interaction of science, scientific knowledge, scientific data and information (general idea modified by the authors, not published yet)

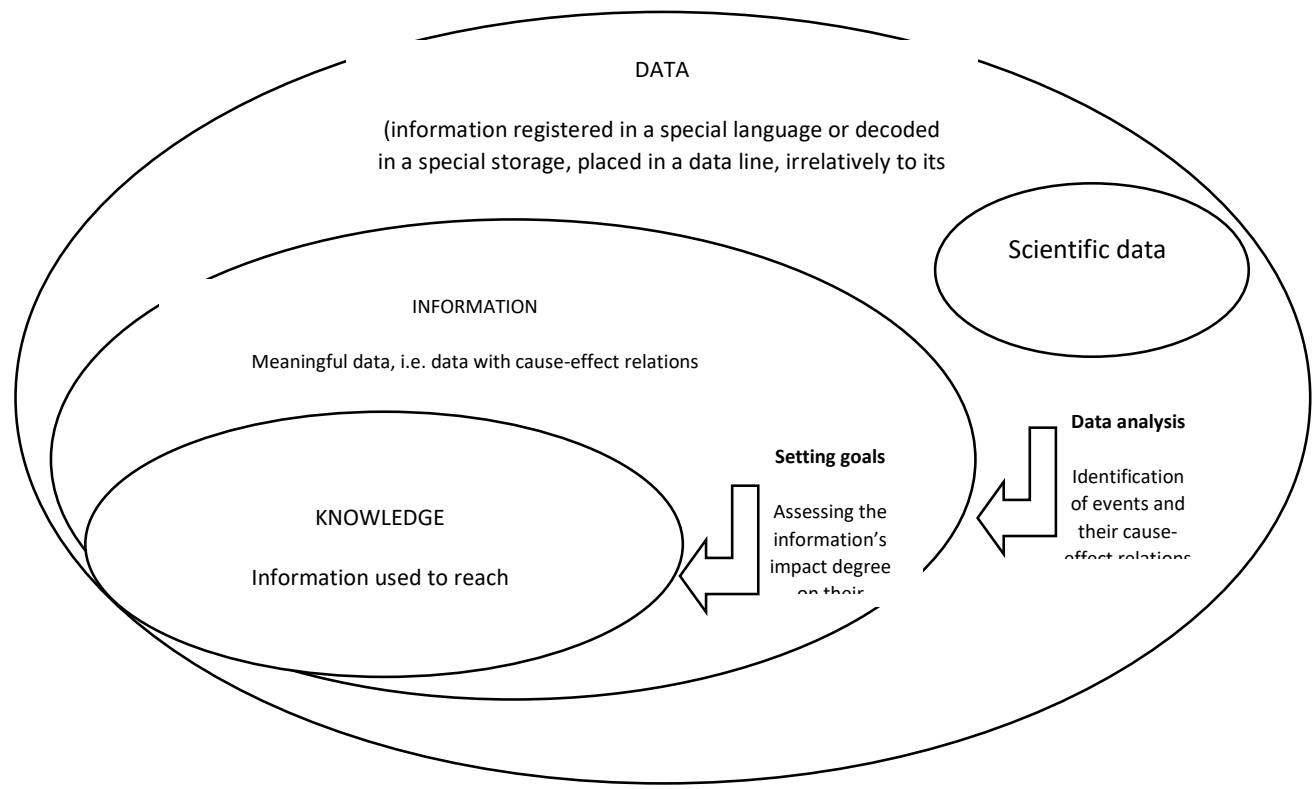

In this format, it is also obvious that the manufacturer of the product (the result of applied research) becomes a monopolist in the practical use of the information produced by him. Applying this information in material production, he will receive 
an excess of profit exceeding its average amount per capital invested in production. Such a monopoly on the use of scientific and technical information for production purposes is expressed in various legal forms like patents, licenses, know-how, etc. A license buyer producing products in a socially beneficial division of labor can make a medium-sized profit, and the monopolist's competitors seek to achieve their own inventions that help overcoming the advantages of existing patents. This kind of activity imitating the fact that new information is produced, is widespread during periods when patents and licenses become more expensive. In this period, the value of the cumulative social costs of technical development increases, and its growth rates decrease. The level of costs of imitators following the pioneering leaders (innovators, according to Schumpeter terminology) averages $65-70 \%$ of the cost of these leaders (Schumpeter, 2007).

In this regard, it is worth noting that the modern progress of information technologies has contributed to the growth of knowledge, ensuring its availability and increasing the ability to use and disseminate knowledge in the socio-economic field of society. Since knowledge is also a public good (initially national, but then rapidly international), from this point of view, we should note a change in the structure of the national wealth of developed countries (Table 1).

Table 1. Changes in the structure of the national wealth of developed countries, \% (Tukavkin, 2014)

\begin{tabular}{|l|l|l|l|l|l|l|l|}
\hline \multirow{2}{*}{$\begin{array}{l}\text { World } \\
\text { average } \\
\text { components } \\
\text { of national } \\
\text { wealth }\end{array}$} & \multicolumn{6}{|l|}{ Composition of national wealth by year, \% } \\
\cline { 2 - 9 } & 1900 & 1950 & 1960 & 1970 & 1980 & 2010 & $\begin{array}{l}2015 \\
\text { (forecast) }\end{array}$ \\
\hline $\begin{array}{l}\text { Nature } \\
\text { capital }\end{array}$ & 44 & 43 & 38 & 23 & 18 & 14 & 8 \\
\hline $\begin{array}{l}\text { Produced } \\
\text { capital }\end{array}$ & 36 & 34 & 32 & 27 & 24 & 20 & 12 \\
\hline $\begin{array}{l}\text { Human } \\
\text { capital }\end{array}$ & 20 & 23 & 30 & 50 & 58 & 66 & 80 \\
\hline
\end{tabular}

At the same time, for knowledge, the relevance determines the level of its demand; the level of demand depends on the reliance. Therefore, sometimes there is a situation when a selected knowledge is not necessary for everyone. This circumstance affects the fact that a significant number of discoveries, inventions and ideas produced by people turn out to be unclaimed. Here we again return, on the one hand, to the fact that the scientist cannot always create 'unselfishly' but is guided by economic gain. On the other hand, the more knowledge is created, and the more knowledge is required, the more products are offered by the knowledge economy, and therefore it is obvious that the work of both scientists and those who supply this knowledge to end users (teaching scientists etc.) is also important.

\section{References:}


Barber, B. 1952. Science and the Social Order. Glencoe, 126-129.

Baturin, V.K. 2010. Myth and space of Science. Space and time, 2, 36-42.

Becker, G.S. 1987. Economic Analysis and Human Behavior. Advances in Behavioral Sciences, Norwood (N.J.), Ablex Publ. Corp., v.1, 3-17.

Belikova, K.M. 2012. The legal regime of consumer protection in MERCOSUR countries: some aspects of information security. Bulletin of the Kalmyk University, 4(16), 107 113.

Belikova, K.M. 2013. The objectives of the methodology of comparative legal research in the field of private law in the modern period. Methodology of comparative legal research. Zhidkovskie chteniya: Proceedings of the All-Russian Scientific Conference. Moscow, March 30, RUDN, 339-346.

Bokanov, A.A. 2010. The concept of information in modern economics. Bulletin of the Military University, 1(21), 120-126.

Bulgakov, S.N. 1990. Philosophy of economy. Moscow, Science publ., 139.

Coase, R.N. 1937. The Nature of The Firm. The Economics, 4, 386-405.

Filippova, S.Yu. 2018. The science of civil law as an object of civil studies. D.Sc., thesis.

Hart, A. 1942. Risk, Uncertainty and the Unprofitability of Compound Probabilities. Studies in Mathematical Economics and Econometrics. University of Chicago Press, 12-25.

Ioffe, O.S. 2000. The development of civil thought in the USSR (Part I) and the development of civil thought in the USSR (Part II). Selected works on civil law: From the history of civil thought. Civil relationship. Criticism of the theory of "economic law", Moscow, Statute, 161-512.

Knight, F. 2000. Risk, Uncertainty and Profit to the Keisure. Available online: https://www.econlib.org/library/Knight/knRUP.html?chapter_num=3\#book-reader

Kuhn, T.S. 1977. The structure of scientific revolutions. Moscow, Progress publ., 300.

Lvov, Yu.A. 1992. Fundamentals of Economics and Business Organization. St Petersburg, 136.

Maiminas, E. 1997. The Information Society and the Paradigm of Economic Theory. Issues of Economics, 11, 88.

Merton, R.K. 1973. The Sociology of Science. University of Chicago Press, 267-278.

Mirskaya, E.Z. 2005. R.K. Merton and the ethos of classical science. Philosophy of science and technology, 1, 11-28.

RUDN. 2018. Personal lecturer's page. Available online: http://web-local.rudn.ru/weblocal/prep/rj/?id=1920

Schumpeter, J.A. 2007. The Theory of Economic Development. Capitalism, socialism, democracy. Moscow, Eksmo, 864.

Shershenevich, G.F. 2003. The science of civil law in Russia. Moscow, Statute, 250.

Stigler, G.J. 1976. Do the Economists Matter? Southern Economic Journal, 42, 347-354.

Stonier, T. 1986. The Wealth of Information: A Profile of the Post-Industrial Economy. New technological wave in the West. Moscow, Progress, 395.

Tukavkin, I.N. 2014. Economics of knowledge. Vestnik of Samara State University, 6(117), 145-150. 